\title{
Degree of Sporulation (SP) and Normalized Difference Vegetation Index (NDVI) as Important Parameter for Characterizing Field Resistance against Cercospora Leaf Spot (CLS) in Mungbean
}

\author{
Priyanka Choudhary* \\ Department of Mycology and Plant Pathology, Institute of Agricultural Sciences, BHU, \\ Varanasi, India \\ *Corresponding author
}

\begin{abstract}
A B S T R A C T
Keywords

Cercospora Leaf Spot, Kopargaon, ML1720,

Recombinant inbred lines, AUDPC

Article Info

Accepted:

08 December 2020

Available Online:

10 January 2021

A total of 190 recombinant inbred lines (RILs) of mung bean along with parents Kopargaon (susceptible) and ML1720 (resistant) were screened for resistance to Cercospora canescens during three consecutive years $(2016,2017$, and 2018) at farm as well as polyhouse. Bartlett's test for homogeneity of variance revealed heterogeneity in data $($ at $\mathrm{p}<0.05)$. ANOVA revealed significant variation $($ at $\mathrm{p}<0.001)$ among the genotypes for various resistance components. Estimates of Correlation coefficient $($ at $\mathrm{p}<0.001)$ and multiple regression analysis both concluded that Degree of sporulation (SP) and Normalized Difference Vegetation Index (NDVI) are the important parameter for characterizing field resistance against Cercospora Leaf Spot (CLS) of mungbean. Disease severity calculated as AUDPC varied significantly across the year and location. The genotype $\times$ environment interactions exerted significant influence (at $\alpha=0.001$ ) which could be reduced by increasing the number of test locations.
\end{abstract}

\section{Introduction}

Around $28.8 \%$ (around 0.3 billion) of Indian are vegetarian which equivocally advocates the importance of pulse protein in Indian diet, in particular and Indian economy, in general (Akibode and Maredia, 2012; Singh et al., 2016). The pace of its exploration in terms of research has always been slow. Among the thirteen pulses grown in India, mung bean or green gram [Vigna radiata (L.) Wilczek] belonging to subgenus Ceratotropis is a selfpollinated, diploid $(2 n=2 x=22)$, short duration pulse/grain legume having579 Mbp genome size (Nair et al., 2019). It is a widely cultivated crop in Southern and Southeast Asia particularly the humid tropics where Cercospora leaf spot disease (CLS) is a key constraint of socioeconomic importance to its production (Mew et al., 1975). Occurrence of disease coincides with reproductive phase of crop (Vakili, 1977) leading to considerable yield loss (Iqbal et al., 1995) which in turn have been compounded by the evolving pathogenic variants of $C$. canescens (Shanmugasundaram, 1987; Chand et al., 2012). 
Hence, exploiting the host plant resistance or tolerance to CLS coupled with higher yields are attributes to be explored. In this context, the present study investigates the important components of CLS resistance for its inclusion in resistance breeding programs. Different components of quantitative resistance or partial resistance in different crops to CLS have already been identified (Aquino et al., 1995, Foster et al., 1980, Ricker et al., 1985). Longer latent periods, lower lesion number and reduced capacity for sporulation (Parlevliet, 1979; Nevill, 1981; Ricker et al., 1985; Rossi et al., 1999) as well as NDVI readings (Alisaac et al., 2018; Robinson et al., 2019) have been identified as components of rate reducing resistance against diseases in various crops.

Characterization of the components CLS disease resistance in mung bean was done, where parents with maximum divergence to CLS reaction along with their 190 RILs (non segregating population) were taken into account. This study would led to better understanding of quantitative resistance in mungbean/Cercospora interaction and pave way for future studies in molecular mapping in mung bean CLS resistance breeding program.

\section{Materials and Methods}

\section{Planting materials}

Experimental germplasm consisted of two mung bean parents Kopargaon (susceptible) a widely adopted cultivar, susceptible to CLS whereas, ML1720 a mungbean line along with their 190 recombinant inbred lines (RILs)

\section{Experimental design}

Experiment was conducted inalpha lattice design with two replications. Field sowing of mungbean line was done in first week of August, while polyhouse sowing was done a week after field sowing. Seeds were sown on mounds with spacing of $20 \times 30 \mathrm{~cm}$. The experiment was carried out in field and polyhouse in two replication over three consecutive years to analyze whether significant variation existed for environment, treatment and genotype $\times$ environment.

\section{Inoculum preparation and artificial inoculation of CLS}

A pathogenic strain of $C$. canescens 'MTCC$10835^{\prime}$ has been used in the present study. Mass culturing and artificial inoculation was done as per Chand et al (2013). The inoculum (spore suspension) for artificial inoculation was prepared from 25 days old colonized sorghum grains $(200 \mathrm{~g})$ by soaking in 1 liter of sterilized water for 5 minutes. These grains were agitated thoroughly in water to dislodge the spores and filtered through two fold muslin cloths.

The inoculum $\left(10^{4}\right.$ spore $\left.\mathrm{ml}^{-1}\right)$ was delivered on mungbean leaves at flowering stage by spraying with a knapsack sprayer between 16.00 and18.00 hours (Chand et al., 2013). The following morning at 07.00 hours field was irrigated to maintain high humidity. The field was irrigated after every two days in case of no rain, to maintain the humidity.

\section{Screening for Disease severity}

Disease was scored first when most of the lines showed the disease symptoms, second, third and fourth disease scoring was performed at 5, 4 and 3 days interval respectively by adopting the 1-9scale (where, $1=$ no infection, $2=$ upto $10 \%, 3=10.1$ to $20 \%, 4=20.1$ to $30 \%, 5=30.1$ to $40 \%, 6=$ 40.1 to $50 \%, 7=50.1$ to $65 \%, 8=65.1$ to $80 \%$ and $9=$ above $80 \%$ disease severity) and the Area Under Disease Progress Curve 
(AUDPC) was calculated using formula given by Shaner and Finnay (1977):

$$
\left.\sum_{i=1}^{n}[\mathrm{YYi}+(\mathrm{Yi}+1)\} / 2\{(\mathrm{ti}+1)-\mathrm{ti}\}\right]
$$

Where, $\mathrm{Yi}=$ disease level at time $\mathrm{ti},(\mathrm{ti}+1)-\mathrm{ti}=$ Time (days) between two lesion scores, $\mathrm{n}=$ number of observations (score).

\section{Data Collection for resistance components}

Incubation period (IP) by subtracting the inoculation day from day to appearance of the first lesion (Aquino et al., 1995); Latent period (LP) by subtracting inoculation day from day to appearance of first Degree of sporulation (Aquino et al., 1995); Degree of Sporulation (SP) by manual counting of sporulated lesion was done 35 days after inoculation on tagged leaves of each plant (Smith, 1980). MPLS (maximum percentage lesion sporulating) $=$ number of lesions sporulated by 35 day after inoculation /total number of lesions counted by $25^{\text {th }}$ day after inoculation (LN) was adopted from Johnston et al (1986). Normalized Difference Vegetation Index (NDVI) value would be taken at three different time point before, during and after biotic stress.

$\mathrm{NDVI}=\left(\mathrm{R}_{\mathrm{NIR}}-\mathrm{R}_{\mathrm{RED}}\right) /\left(\mathrm{R}_{\mathrm{NIR}}+\mathrm{R}_{\mathrm{RED}}\right)$

Where, $R_{\text {NIR }}$ and $R_{R E D}$ is light reflection at near infra-red and red region of spectrum respectively. Measurements would be taken using hand held NDVI meter (Verhulst et al., 2010a, 2010b)

\section{Data analysis}

All the data were tested for the normality using Sapiro -Wilkin test. Non normal data was normalized by square root transformation then Homogeneity of error variances of nonsegregating generations was tested by using
Bartlett's test (Bartlett, 1937), and when the variances were heterogeneous at $1 \%$ and $5 \%$ level of significance the data was transformed by dividing observations of each environment/year by the square root of MSE of that environment/year which makes the error variances homogeneous and pooled analysis was performed on transformed data. SAS 9.3 version was utilized for ANOVA, correlation and regression calculations.

\section{Results and Discussion}

\section{Research findings}

All the data obtained for different variables showed normal distribution except for Degree of sporulation (SP), hence square root transformation was carried for SL to get normalized data. Bartlett's test for Homogeneity of variance (table 1) revealed that data for all traits were heterogeneous at $5 \%$ level of significance when pooled for field and polyhouse trails over three consecutive years. Hence data was transformed and this transformed pooled data was used for further analysis. Mean values along with standard deviation, standard error and normality test are presented in table 1.

\section{Significant treatment $x$ environment interaction}

Existence of highly significant variation for year (f (df 5,1146; $\alpha=0.001)$ ), treatment(f (df191,1146; $\alpha=0.001$ ), and the treatment $\mathrm{x}$ environment ( $\mathrm{f}_{\text {(df }}$ 955,1146; $\alpha=0.001$ ) interactions (table 2) indicated that the treatment interacted considerably with the environmental changes.

\section{Correlation and Regression analysis}

The estimates of Correlation coefficient (table 3) among resistance components showed that all the components were moderatly to highly correlation $(p<0.001)$ with each other. A 
significantly high and positive correlation between AUDPC and SL $(r=0.837 ; \mathrm{p}<0.001)$ while high and negative correlation between AUDPC and NDVI ( $\mathrm{r}=-0.934 ; \mathrm{p}<0.001)$ was noticed underlining the importance of these traits as components of quantitative resistance in mungbean against CLS. Multiple regression analysis (table 4) clearly enumerated that of AUDPC depended significantly on SP $(p<0.078)$ and NDVI $(p<$ 0.000 ) strengthening the fact that traits SP and NDVI are important components of quantitative resistance in mungbean against CLS.

Table.1 Estimates of Mean, SE, Bartlett's test Chi-Square values and Normality test values for resistance components

\begin{tabular}{|c|c|c|c|c|c|c|c|c|c|c|}
\hline \multirow[t]{3}{*}{ Traits } & \multicolumn{3}{|c|}{ Field } & \multicolumn{3}{|c|}{ Polyhouse } & \multirow{2}{*}{$\begin{array}{l}\text { Bartlett's } \\
\text { test @ } \\
\mathrm{DF}(5), \\
\mathrm{p}<0.05\end{array}$} & \multicolumn{3}{|c|}{ Transformed pooled data } \\
\hline & 2016 & 2017 & 2018 & 2016 & 2017 & 2018 & & & & \\
\hline & Mean \pm S. E & $\underset{\mathrm{E}}{\operatorname{Mean} \pm \mathrm{S}}$ & $\underset{\mathrm{E}}{\operatorname{Mean} \pm \mathrm{S}}$ & $\begin{array}{c}\text { Mean } \pm S \\
\text { E }\end{array}$ & $\begin{array}{c}\text { Mean } \pm S \\
E\end{array}$ & $\begin{array}{c}\text { Mean } \pm S \\
E\end{array}$ & $\begin{array}{l}\text { Chi- } \\
\text { Square } \\
\text { values }\end{array}$ & Mean \pm S. E & $\begin{array}{l}\text { Shapiro } \\
\text { wilk-w }\end{array}$ & $\begin{array}{l}\text { Shapiro } \\
\text { wilk-p }\end{array}$ \\
\hline AUDPC & $\begin{array}{c}346.88 \pm 7 \\
78\end{array}$ & $\begin{array}{c}341.75 \pm 8 \\
84\end{array}$ & $\begin{array}{c}323.69 \pm 8 \\
66\end{array}$ & $\begin{array}{c}327.69 \pm 8 \\
.94\end{array}$ & $\begin{array}{c}324.55 \pm 9 \\
.07\end{array}$ & $\begin{array}{c}288.59 \pm 9 \\
10\end{array}$ & $849.33^{* *}$ & $20.71 \pm 0.55$ & 0.979 & 0.005 \\
\hline IP & $\begin{array}{c}12.52 \pm 0.1 \\
8\end{array}$ & $\begin{array}{c}12.28 \pm 0.1 \\
8\end{array}$ & $\begin{array}{c}12.30 \pm 0.1 \\
8\end{array}$ & $\begin{array}{c}12.16 \pm 0 \\
18\end{array}$ & $\begin{array}{c}12.50 \pm 0 \\
18\end{array}$ & $\begin{array}{c}12.75 \pm 0.1 \\
8\end{array}$ & $778.71^{* *}$ & $95.39 \pm 1.41$ & 0.984 & 0.027 \\
\hline LP & $\begin{array}{c}23.45 \pm 0.1 \\
9\end{array}$ & $\begin{array}{c}23.51 \pm 0.1 \\
9\end{array}$ & $\begin{array}{c}23.37 \pm 0.1 \\
9\end{array}$ & $\begin{array}{c}23.36 \pm 0 \\
19\end{array}$ & $\begin{array}{c}23.33 \pm 0 \\
19\end{array}$ & $\begin{array}{c}23.69 \pm 0.1 \\
9\end{array}$ & $221.01^{* *}$ & $115.19 \pm 0.92$ & 0.987 & 0.073 \\
\hline $\mathbf{L N}$ & $\begin{array}{c}77.49 \pm 1.8 \\
8\end{array}$ & $\begin{array}{c}74.68 \pm 2.1 \\
5\end{array}$ & $\begin{array}{c}78.39 \pm 1.8 \\
2\end{array}$ & $\begin{array}{c}76.23 \pm 1 \\
79\end{array}$ & $\begin{array}{c}78.34 \pm 2 \\
39\end{array}$ & $\begin{array}{c}75.91 \pm 1.8 \\
0\end{array}$ & $1932.44^{* *}$ & $24.61 \pm 0.62$ & 0.981 & 0.012 \\
\hline MPLS & $\begin{array}{c}43.43 \pm 1.3 \\
5\end{array}$ & $\begin{array}{c}46.64 \pm 1.3 \\
7\end{array}$ & $\begin{array}{c}40.37 \pm 1.2 \\
3\end{array}$ & $\begin{array}{c}43.68 \pm 1 \\
27\end{array}$ & $\begin{array}{c}46.69 \pm 1 . \\
67\end{array}$ & $\begin{array}{c}43.62 \pm 1.3 \\
2\end{array}$ & $1719.95^{* *}$ & $12.35 \pm 0.37$ & 0.992 & 0.339 \\
\hline $\begin{array}{c}\text { SP(sqrt } \\
\text { ) }\end{array}$ & $5.67 \pm 0.15$ & $5.61 \pm 0.15$ & $5.50 \pm 0.15$ & $\begin{array}{c}5.71 \pm 0.1 \\
4\end{array}$ & $\begin{array}{c}5.72 \pm 0.1 \\
4\end{array}$ & $5.68 \pm 0.14$ & $2342.13^{* *}$ & $34.14 \pm 0.85$ & 0.994 & 0.615 \\
\hline NDVI & $8.28 \pm 0.02$ & $8.39 \pm 0.03$ & $8.23 \pm 0.03$ & $\begin{array}{c}7.37 \pm 0.0 \\
6\end{array}$ & $\begin{array}{c}7.19 \pm 0.0 \\
6\end{array}$ & $7.75 \pm 0.06$ & $1571.51^{* *}$ & $99.05 \pm 0.48$ & 0.973 & 0.001 \\
\hline
\end{tabular}

AUDPC = Area Under Disease Progress Curve; IP = Incubation Period (Days); LP = Latent Period (Days); LN=Lesion number; MPLS = Maximum percentage sporulating lesion and SP = Degree of Sporulation

Table.2 Estimates of ANOVA and CD for resistance components (transformed pooled data)

\begin{tabular}{|c|c|c|c|c|c|c|c|c|}
\hline $\begin{array}{c}\text { Source of } \\
\text { Variation }\end{array}$ & \multirow{2}{*}{ DF } & AUDPC & IP & LP & LN & MPLS & SP (sqrt) & NDVI \\
\cline { 2 - 9 } & & M S & M S & M S & M S & M S & M S & M S \\
\hline Year & 5 & $224756.2^{* *}$ & $4785490^{* *}$ & $636668.8^{* *}$ & $239566.1^{* *}$ & $44164.69^{* *}$ & $473116.3^{* *}$ & $1775328^{* *}$ \\
\hline Rep within Year & 6 & 34.358 & 471.513 & 134.383 & 3.453 & 10.615 & 11.65 & 126.3741 \\
\hline Treatment & 191 & $702.314^{* *}$ & $4564.736^{* *}$ & $1953.048^{* *}$ & $895.352^{* *}$ & $307.615^{* *}$ & $1678.733^{* *}$ & $530.229^{* *}$ \\
\hline Year $\times$ Treat & 955 & $164.147^{* *}$ & $1063.634^{* *}$ & $41.08^{* *}$ & $210.186^{* *}$ & $48.365^{* *}$ & $297.963^{* *}$ & $89.091^{* *}$ \\
\hline Pooled Error & 1146 & 1 & 1.007 & 0.995 & 1.002 & 1 & 0.997 & 0.989 \\
\hline CD (Years) & 1.092 & 4.044 & 2.159 & 0.346 & 0.607 & 0.636 & 6.62 \\
\hline CD (Treatments) & 13.496 & 34.355 & 6.752 & 15.272 & 7.326 & 18.183 & 9.943 \\
\hline CD (Year (Treatment) & 2.58 & 2.589 & 2.574 & 2.583 & 2.58 & 2.577 & 2.567 \\
\hline
\end{tabular}

**significant at $\mathrm{p}<0.001$

Trait abbreviations as mentioned in Table 1 
Table.3 Estimates of Correlation coefficient among the resistance components (transformed pooled data)

\begin{tabular}{|c|c|c|c|c|c|c|}
\hline Traits & AUDPC & IP & LP & LN & MPLS & SP (sqrt) \\
\hline IP & $-0.722^{* *}$ & & & & & \\
\hline LP & $-0.740^{* *}$ & $0.991^{* *}$ & & & & \\
\hline LN & $0.689^{* *}$ & $-0.715^{* *}$ & $-0.723^{* *}$ & & & \\
\hline MPLS & $0.763^{* *}$ & $-0.651^{* *}$ & $-0.675^{* *}$ & $0.535^{* *}$ & & \\
\hline SP (sqrt) & $0.837^{* *}$ & $-0.766^{* *}$ & $-0.788^{* *}$ & $0.846^{* *}$ & $0.898^{* *}$ & \\
\hline NDVI & $-0.934^{* *}$ & $0.689^{* *}$ & $0.710^{* *}$ & $-0.690^{* *}$ & $-0.742^{* *}$ & $-0.823^{* *}$ \\
\hline
\end{tabular}

**significant at $\mathrm{p}<0.001$

Trait abbreviations as mentioned in Table 1

Table.4 Estimates of Multiple regression analysis among the resistance components with AUDPC as dependent variable (transformed pooled data)

\begin{tabular}{|c|c|c|c|c|}
\hline Traits & Regression Coefficients & Standard Error & t-value & Significance \\
\hline IP & -0.071 & 0.075 & -0.939 & 0.349 \\
\hline LP & 0.045 & 0.119 & 0.376 & 0.707 \\
\hline LN & -0.197 & 0.133 & -1.485 & 0.139 \\
\hline MPLS & -0.281 & 0.27 & -1.04 & 0.299 \\
\hline SP (sqrt) & 0.327 & 0.184 & 1.772 & $\mathbf{0 . 0 7 8}$ \\
\hline NDVI & -0.85 & 0.05 & -17.025 & $\mathbf{0}$ \\
\hline Constant & 103.633 & & & \\
\hline
\end{tabular}

Trait abbreviations as mentioned in Table 1

\section{Genotype $\times$ Environment interaction}

Genotype $\times$ Environment interaction accounts for selection of suitable test environments to maximize gain from selection (Yan et al., 2011). For each trait under study there was differential response of the genotype to environmental changes. Presence of significant environment $\times$ genotype interaction in response to disease resistance in our study was in accordance with the previously reported works on barley/net blotch interaction studied by Cherif et al (2010) as well as recent works on pea/leaf rust interaction studied by Das et al., (2019) as well as mung bean/ CLS interaction studied by Das et al., (2020).

\section{Trait characterizing resistance to CLS in} mung bean

The correlation results among the components of resistance (table 3 ) were in agreement with that obtained by Aquino et al., (1995) in groundnut for late leaf spot where, AUDPC values were highly correlated with LP, IP, SP and MPLS. Similar results were presented by Johnston et al., (1986), Dwivedi et al., (2002) showing high correlation of AUDPC with LP and MPLS. In accordance with our results, higher negative associations between NDVI and AUDPC have been advocated by Robinson et al (2019) and Alisaac et al., (2018). Hence, selection for longer IP and LP; lower LN, SP and MPLS as well as higher NDVI would effectively delay the CLS 
development in the field (Waliyar et al., 1993; Aquino et al., 1995; Dwivedi et al., 2002; Robinson et al., 2019).

In conclusion the evaluating and identifying components of rate reducing resistance in vivo is tedious and lengthy process. Existence of variability among the genotypes and significant correlation among all the components of quantitative resistance under study showed that they might be exploited in contributing towards the slowing of epidemics. Resistance resulting in lower AUDPC, higher IP and LP, lower LN, SL and MPLS would contribute to slow disease progression. In our study, SL and NDVI have emerged as main component characterizing the resistance in mung bean/ Cercospora canescens interaction. Furthermore, significant genotype $\times$ environment interactions, reveals increment in number of location for effective screening for quantitative disease resistance of large population not only mung bean but other crops also against leaf spot diseases.

\section{Acknowledgment}

Author is thankful to ICAR, New Delhi for SRF fellowship and her Ph.D. mentor Prof. R. Chand, Department of Mycology and Plant pathology for providing the mungbean parental lines and the pathogenic strain of Cercospora canescens for the present research work. Author is highly obliged to Dr. A. K. Singh, Department of Genetics and Plant Breeding for advice during manuscript revision.

\section{References}

Alisaac, E., Behmann, J., Kuska, M. T., Dehne, H. W., and Mahlein, A. K. 2018.Hyperspectral quantification of wheat resistance to Fusarium head blight: comparison of two Fusarium species. European Journal of Plant Pathology, 152(4), 869-884.

Aquino, V. M., Shokes, F. M., Gorbet, D. W., and Nutter, F. W. 1995.Late leaf spot progression on peanut as affected by components of partial resistance. Plant disease, 79(1), 74-78.

Bartlett, M. S. 1937. Some examples of statistical methods of research in agriculture and applied biology. Supplement to the Journal of the Royal Statistical Society, 4(2), 137183.

Chand, R. A. M. E. S. H., Kumar, P. R. A. B. H. A. T., Singh, V. I. N. E. E. T. A., and Pal, C. H. H. A. T. T. A. R. 2013. Technique for spore production in Cercospora canescens. Indian Phytopthol, 66, 159-163.

Chand, R., Singh, V., Pal, C., Kumar, P., and Kumar, M. 2012. First report of a new pathogenic variant of Cercospora canescens on mungbean (Vignaradiata) from India. New Dis. Rep, 26(6), 20440588 .

Cherif, M., Rezgui, S., Devaux, P., and Harrabi, M. 2010.Genotype X environment interactions and heritability of quantitative resistance to net blotch in Tunisian barley. Journal of Plant Breeding and Crop Science, 2(5), 110-116.

Das, A., Gupta, S., Parihar, A. K., Saxena, D., Singh, D., Singha, K. D.,. .. and Chandra, S. 2019. Deciphering genotype-by-environment interaction for targeting test environments and rust resistant genotypes in field pea (Pisumsativum L.). Frontiers in plant science, 10, 825.

Das, A., Gupta, S., Parihar, A. K., Singh, D., Chand, R., Pratap, A., and Kushwaha, K. P. S. 2020. Delineating Genotypex Environment interactions towards durable resistance in mungbean against Cercospora leaf spot (Cercospora 
canescens) using GGE biplot. Plant Breeding, 139(3), 639-650.

Dwivedi, S. L., Pande, S., Rao, J. N., and Nigam, S. N. 2002. Components of resistance to late leaf spot and rust among interspecific derivatives and their significance in a foliar disease resistance breeding in groundnut (Arachishypogaea

L.). Euphytica, 125(1), 81-88.

Fery, R. L., and Dukes, P. D. 1977. An assessment of two genes for Cercospora leaf spot resistance in the Southern pea (Vignaunguiculata

(L.)Walp.). HortScience, 12(5), 454456.

Govaerts, B., and Verhulst, N. 2010. The normalized difference vegetation index (NDVI) Greenseeker (TM) handheld sensor: toward the integrated evaluation of crop management part A: concepts and case studies.

Govaerts, B., and Verhulst, N. 2010. The normalized difference vegetation index (NDVI) Greenseeker (TM) handheld sensor: toward the integrated evaluation of crop management part A: concepts and case studies.

Iqbal, S. M., Ghafoor, A., Bashir, M., and Malik, B. A. 1995.Estimation of losses in yield components of mungbean due to Cercospora leaf spot. Pakistan $J$ Phytopathol, 7, 80-81.

Johnston, C. S., Beute, M. K., and Ricker, M. D. 1986. Relationship between components of resistance and disease progress of early leaf spot on virginiatype peanut. Phytopathology, 76(5), 495-499.

Kumar, S., Röder, M. S., Singh, R. P., Kumar, S., Chand, R., Joshi, A. K., and Kumar, U. 2016. Mapping of spot blotch disease resistance using NDVI as a substitute to visual observation in wheat (Triticum aestivum L.). Molecular breeding, 36(7), 95.
Madhavan Nair, R., Pandey, A. K., WAR, A. R., Hanumantharao, B., Shwe, T., Alam, A. K. M. M.,. ..and Douglas, C. A. 2019. Biotic and abiotic constraints in mungbean production-progress in genetic improvement. Frontiers in Plant Science, 10, 1340.S. Akibode, M. K. Maredia, "Global and regional trends in production, trade and consumption of food legume crops," Department of Agricultural, Food, and Resource Economics, Michigan State University, 2012.

Mew, I. P., Wang, T. C., and Mew, T. W. 1975. Inoculum production and evaluation of mung bean varieties for resistance to Cercospora canescens. Plant Disease Reporter, 59(5), 397-401.

Nevill, D. J. 1981. Components of resistance to Cercospora arachidicola and Cercosporidiumpersonatum in groundnuts. Annals of Applied Biology, 99(1), 77-86.

Parlevliet, J. E. 1979. Components of resistance that reduce the rate of epidemic development. Annual review of phytopathology, 17(1), 203-222.

Ricker, M. D., Beute, M. K., and Campbell, C. L. 1985.Components of resistance in peanut to Cercospora arachidicola. Plant Disease, 69(12), 1059-1064.

Robinson, N. A. 2019. Use of Normalised Difference Vegetation Index (NDVI) to assess tolerance of wheat cultivars to root-lesion nematodes (Pratylenchusthornei) (Doctoral dissertation, University of Southern Queensland).

Rossi, V., Battilani, P., Chiusa, G., Giosue, S., Languasco, L., and Racca, P. 1999. Components of rate-reducing resistance to Cercospora leaf spot in sugar beet: incubation length, infection efficiency, lesion size. Journal of Plant Pathology, 
25-35.

Shaner, G., and Finney, R. E. 1977.The effect of nitrogen fertilization on the expression of slow-mildewing resistance in Knox wheat. Phytopathology, 67(8), 1051-1056.

Shanmugasundaram, S. 1987. Mungbean varietal improvement. AVRDC, Taiwan, 1-49.

Singh, D., Shahi, B., and Singh, K. M. 2016. Trends of pulses production, consumption and import in india: current scenario and strategies. Brajesh and Singh, Krishna M., Trends of Pulses Production, Consumption and Import in India: Current Scenario and Strategies (May 15, 2016).

Smith, D. H. 1980. Management of Peanut
Foliar Dis. Plant Dis, 64, 357.

Vakili, N. G. 1977. Field screening of cowpeas for Cercospora leaf spot resistance. Tropical Agriculture, 54(1), 69-76.

Waliyar, F., McDonald, D., SubbaRao, P. V., and Reddy, P. M. 1993.Components of resistance to an Indian source of Cercospora arachidicola in selected peanut lines. Peanut Science, 20(2), 9396.

Yan, W., Pageau, D., Frégeau-Reid, J., and Durand, J. 2011.Assessing the representativeness and repeatability of test locations for genotype evaluation. Crop Science, 51(4), 16031610.

\section{How to cite this article:}

Priyanka Choudhary. 2021. Degree of Sporulation (SP) and Normalized Difference Vegetation Index (NDVI) as Important Parameter for Characterizing Field Resistance against Cercospora Leaf Spot (CLS) in Mungbean. Int.J.Curr.Microbiol.App.Sci. 10(01): 537-544.

doi: https://doi.org/10.20546/ijcmas.2021.1001.065 